\title{
Conservative versus surgical management for patients with rotator cuff tears: a systematic review and META-analysis
}

Umile Giuseppe Longo ${ }^{1 *} \mathbb{D}$, Laura Risi Ambrogioni ${ }^{1}$, Vincenzo Candela', Alessandra Berton ${ }^{1}$, Arianna Carnevale ${ }^{1,2}$, Emiliano Schena ${ }^{2}$ and Vincenzo Denaro ${ }^{1}$

\begin{abstract}
Background: This study aims to compare conservative versus surgical management for patients with full-thickness $\mathrm{RC}$ tear in terms of clinical and structural outcomes at 1 and 2 years of follow-up.

Methods: A comprehensive search of CENTRAL, MEDLINE, EMBASE, CINAHL, Google Scholar and reference lists of retrieved articles was performed since the inception of each database until August 2020. According to the Cochrane Handbook for Systematic Reviews of Interventions, two independent authors screened all suitable studies for the inclusion, extracted data and assessed risk of bias. Only randomised controlled trials comparing conservative and surgical management of full-thickness RC tear in adults were included. The primary outcome measure was the effectiveness of each treatment in terms of Constant-Murley score (CMS) and VAS pain score at different time points. The secondary outcome was the integrity of the repaired tendon evaluated on postoperative MRI at different time points. The GRADE guidelines were used to assess the critical appraisal status and quality of evidence.

Results: A total of six articles met the inclusion criteria. The average value of CMS score at 12 months of follow-up was $79.2 \pm 13.7$ in the surgery group and $72.7 \pm 17.2$ in the conservative group. The average value of CMS score at 24 months of follow-up was $80 \pm 15$ in the surgery group and $77 \pm 15$ in the conservative group. Results showed statistically significant differences between the CMS measured at one year of follow-up in favour of surgical RC repair compared with patients treated conservatively $(P=0.003)$. No significant differences were demonstrated in terms of CMS at 24 months of follow-up $(P=0.15)$. The mean of VAS pain score at 12 months of follow-up was $1.4 \pm 1.6$ in the surgery group and $2.4 \pm 1.9$ in the conservative group. Quantitative synthesis showed better results in favour of the surgical group in terms of VAS pain score one year after surgery $(-1.08,95 \% \mathrm{Cl}-1.58$ to $-0.58 ; P<0.001)$.

Conclusions: At a 2-year follow-up, shoulder function evaluated in terms of CMS was not significantly improved. Further high-quality level-I randomised controlled trials at longer term follow-up are needed to evaluate whether surgical and conservative treatment provide comparable long-term results.
\end{abstract}

Keywords: Surgery, Surgical treatment, Conservative treatment, Physiotherapy, Rotator cuff, Rotator cuff tear, Rotator cuff repair, Shoulder, Pain

\footnotetext{
* Correspondence: g.longo@unicampus.it

'Department of Orthopaedics and Trauma Surgery, Campus Bio-Medico University of Rome, Via Alvaro del Portillo, 200, 00128 Trigoria, Rome, Italy

Full list of author information is available at the end of the article
}

(c) The Author(s). 2021, corrected publication 2021. Open Access This article is licensed under a Creative Commons Attribution 4.0 International License, which permits use, sharing, adaptation, distribution and reproduction in any medium or format, as long as you give appropriate credit to the original author(s) and the source, provide a link to the Creative Commons licence, and indicate if changes were made. The images or other third party material in this article are included in the article's Creative Commons licence, unless indicated otherwise in a credit line to the material. If material is not included in the article's Creative Commons licence and your intended use is not permitted by statutory regulation or exceeds the permitted use, you will need to obtain permission directly from the copyright holder. To view a copy of this licence, visit http://creativecommons.org/ licenses/by/4.0/. The Creative Commons Public Domain Dedication waiver (http://creativecommons.org/publicdomain/zero/1. 0/) applies to the data made available in this article, unless otherwise stated in a credit line to the data. 


\section{Background}

Shoulder pathologies are incrementing at a rapid rate [1]. Every year in the United States, 4.5 million medical visits are made for shoulder diseases, of which $70 \%$ is mainly due to rotator cuff (RC) tears [1]. Even though $\mathrm{RC}$ tears may be asymptomatic, some patients complain symptoms ranging from minimal discomfort to severe joint pain, muscle weakness and marked dysfunction with significant limitation in the activities of daily living [2]. Approximately $65 \%$ of $\mathrm{RC}$ repairs are performed annually in patients ageing $<65$ years, thus profoundly affecting the working population [3-10].

$\mathrm{RC}$ tears are classified in partial or full-thickness tears according to the severity of the tendon fibres disruption and the communication between the subacromial and glenohumeral space $[9,11]$. The management of $\mathrm{RC}$ tears is a relevant topic with a wide prevalence, but what is the optimal treatment for partial and full-thickness $\mathrm{RC}$ tears is still unclear since both conservative and surgical treatment have strengths and weaknesses [12-17]. Despite the high numbers of procedures performed all over the world, structural failures of RC surgery are very high, ranging from 16 to $94 \%[18,19]$. Moreover, it is not clear whether reattaching the tendon to the bone can avoid the progression of muscle atrophy and degeneration [18]. The surgical treatment of $\mathrm{RC}$ tears is a well-documented therapeutic option for youngers with acute symptomatic partial and full-thickness tears and severe dysfunction [12, 20-22]. In contrast, the conservative treatment is widely used in patients with a degenerative condition of the tendons or tendon disruption of less than $50 \%$ of the entire tendon thickness [23-26]. On the contrary, conservative treatment may predispose patients to continued irreversible tissue degeneration over time. Therefore, $\mathrm{RC}$ tears which initially could be managed as repairable may become irreparable, leading to the need for further treatments and worse results [27]. The duration of non-operative management is one of the most challenging factors of the conservative approach. This type of treatment should be adapted to the patient's characteristics in terms of clinical and structural outcomes, lifestyle, level of functional impairment, and compliance with the physical sessions [28]. However, also the surgical treatment depends on the size of the tear, the quality of the tendon, the staging of the retraction, the tear pattern and the experience of the surgeon [29]. This suggests that several structural and contextual factors can contribute to the success of both conservative and surgical treatment, justifying the considerable heterogeneity and complexity of comparison [27].

To date, only a few randomised controlled trials have been performed to compare the effects of conservative and surgical management. Some of these randomised controlled trials provided results at short-term follow-up ( $\leq 1$ year) $[12,15,30]$. In contrast, others provided results at two years after the intervention [13, 14, 31], and only one provided results at 5 and 10 years of follow-up [13, 31]. In previous meta-analyses, short-term follow-up outcomes for both conservative and surgical RC treatment were compared [32-34]. Results showed limited evidence about the superiority of the surgical treatment over the conservative one, stating the need for studies with medium-term follow-up $(1<$ years $\leq 3)$ and longterm follow-up (years $>3$ ). To date, to the best of our knowledge, meta-analyses at longer term follow-up are not available.

Therefore, this study aimed to compare conservative versus surgical management for patients with fullthickness RC tear in terms of clinical and structural outcomes.

\section{Methods}

\section{Search strategy and study selection}

According to the PRISMA (Preferred Reporting Items for Systematic Reviews and Meta-analyses) checklist and algorithm [35], a comprehensive search of the Cochrane Register of Controlled Trials (CENTRAL), MEDLINE (Ovid), EMBASE (Ovid), CINAHL (EBSCO), Google Scholar and reference lists of retrieved articles was performed. The combination of free-text terms and Medical Subject Headings (MeSH) in title and abstract was used to perform the research. The search strategy was built on the application of Boolean logic operators to the following keywords: ("rotator cuff" OR "rotator cuff tear" OR "rotator cuff injury" OR "non-traumatic tears" $O R$ "rotator cuff rupture" OR "rotator cuff disease") AND ("rotator cuff repair" OR "surgical procedures" OR "rotator cuff surgery" OR "arthroscopy" OR "operative" OR "non operative" OR "conservative" OR "treatment" $O R$ "management"). After duplicates removal, two independent reviewers (L.R.A. and V.C) had verified the suitability of each article published in a peer-reviewed journal for the relevance of title and abstract to the objective of this study without excluding any journal since the inception of each database until August 2020. Studies without abstract or meaningful information were excluded during the study selection process. The independent reviewers conducted an accurate full-text reading of the chosen articles, obtaining data to reduce selection bias. Due to the language skills of the authors, articles in English, French, Spanish, German, and Italian were investigated. Any disagreement among investigators on the inclusion of a study was resolved by the senior investigator (V.D.), who made the final decision. Finally, to avoid potential biases, the selected articles, the list of references and the articles excluded from the study were reviewed, evaluated and discussed by all the authors. 
Articles were included whether they fulfilled the following inclusion criteria: randomised controlled trial, full-thickness rotator cuff tear, and age $\geq 18$. Furthermore, to increase the strength of the study, only level-I studies based on the Oxford Centre of EBM published in peer-reviewed journals were included [36]. Articles were considered ineligible for this study if one of the following exclusion criteria was present: a follow-up period of less than one-year, previous shoulder surgery. Although some contextual and structural factors (e.g. partial or complete rupture, age of tearing, degenerative nature of the disease) may have been important to consider in the eligibility criteria, the heterogeneity of participants in the included studies forced us to broaden the inclusion criteria.

\section{Data extraction}

Extraction data was performed by the two reviewers (U.G.L and L.R.A) using a predetermined form to ensure consistency of appraisal. For each article included in the study, the following data has been extracted: authors, year, study design, level of evidence, sample size, losses at follow-up, number of patients in the surgical and conservative group, sex, age, follow-up, clinical outcomes (Constant-Murley score (CMS), Pain-free abduction, Range of Motions (ROMs), Simple Shoulder Test (SST) score, American Shoulder and elbow surgeons (ASES) score), visual analog scale (VAS) score, retear events and adverse effects.

Our primary outcome measure was the effectiveness of each treatment in terms of clinical outcome at different time points (CMS and VAS pain score). The secondary outcome was the integrity of the repaired tendon evaluated on postoperative MRI at different time points. There were no reported adverse effects.

\section{Data synthesis and statistical analysis}

Continuous variables were reported as mean \pm standard deviation (SD) with 95\% confidence intervals (CI). Dichotomous data were reported as risk ratio (RR) with $95 \% \mathrm{CI}$. In all studies, $P$-value $<0.05$ was considered statistically significant. Whether at least two studies compared the same variables, a random or a fixed effect based on heterogeneity was calculated in a metaanalysis. Review Manager (RevMan, version 5 for Windows; Cochrane Information Management System) was used to perform the meta-analysis. The results of the individual studies and meta-analysis are presented with the forest plots.

\section{Assessment of heterogeneity}

The assessment of heterogeneity was accomplished through the visual examination of forest plots and overlapping CIs, and by I ${ }^{2}$ statistics.
The assessment of the clinical and methodological characteristics of the included studies (e.g. differences in participants, fairness in the number of participants among intervention groups, interventions, losses at follow-up, clinical outcome evaluations) was used to explore the clinical heterogeneity. When clinical heterogeneity was assessed as low, we pooled the data in the meta-analysis. Otherwise, we discussed whether to exclude some studies altogether or include them after a sensitivity analysis.

Between-studies heterogeneity was evaluated in terms of $I^{2}$ index. We considered a $P$ value of less than 0.10 as evidence of heterogeneity. According to the Cochrane Handbook for Systematic Reviews of Interventions, the interpretation of the $I^{2}$ for heterogeneity was as follows:

- 0 to $40 \%$, was not important

- 30 to $60 \%$, represented moderate heterogeneity

- 50 to $90 \%$, represented substantial heterogeneity

- 75 to $100 \%$, represented considerable heterogeneity

A fixed-effect model in the data synthesis was adopted when heterogeneity values were $\leq 60 \%$; otherwise, a random-effects model was used.

\section{Risk of bias}

Two independent reviewers (L.R.A and U.G.L.) assessed the risk of bias for each included study. The Cochrane Risk of Bias has been used as a tool for critical appraisal. Following methods recommended by The Cochrane Collaboration, a domain-based evaluation (random sequence generation; allocation concealment; blinding of participants, personnel and outcome assessors; incomplete outcome data; selective outcome data reporting and other sources of bias) was performed [37]. The following judgments were used: low risk, high risk, or unclear (either lack of information or uncertainty over the potential for bias). Authors resolved disagreements by consensus, and a third author (V.D.) was consulted to resolve disagreements whether necessary.

\section{Quality assessment}

The GRADE (Grading of Recommendations Assessment, Development and Evaluation) guidelines were used to assess the critical appraisal status and quality of evidence of the included randomised controlled trials. The combination of four factors (i.e., study design, study quality, consistency, and directness) provided whether the quality of the evidence was high, moderate, low, or very low. We downgraded the evidence quality from' high quality' by one level for serious risk of bias, inconsistency, indirectness of evidence, imprecision of effect estimates or potential 
publication bias. The following outcomes were included in the' Summary of findings' tables:

- CMS at one year of follow-up

- CMS at two years of follow-up

- VAS pain score at one year of follow-up

\section{Results}

\section{Search results and data extraction}

The search strategy yielded a total of 1467 articles, to which 16 articles were added from the reference list of included studies. After duplicates removing, 1106 articles remained for review. A total of 951 articles were excluded because they did not report specific data on the management of RC tears. The remaining 155 fulltext articles were evaluated; of these, only nine articles were potentially eligible. Of these, only six articles met the inclusion criteria $[12-15,30,31] .3$ of 6 performed by Moosmayer et al. [12, 13, 31], and 2 of $6[14,30]$ performed by Kukkonen et al. are publications of results from the same study group at different follow-up times. For this reason, six studies were included in the meta-analysis, but the patient cohorts from which the data were extracted are three (Fig. 1). The absence of further long term follow-up studies precluded the possibility to compare data from the only available 10year follow-up randomised controlled trial conducted by Moosmayer et al. [13]. Kukkonen et al. included a cohort of patients who underwent physical therapy and subacromial decompression without $\mathrm{RC}$ repair $[14,30]$. Therefore, we excluded data related to this study group, as they did not meet the inclusion criteria. Patients were evaluated at different follow-up periods. In particular, clinical outcomes were reported at 12 months in 3 studies [12, 15, 30], at 24 months in 2 studies [14, 31], at 5 and 10 years in 1 study [13]. MRI was used to report structural outcomes at one year of follow-up in 2 studies [12, 15] and 24 months in 1 study [14]. Ultrasound was used to report structural outcomes at 5 and 10 years in 1 study [13]. Therefore, comparison for clinical outcomes was possible at 1 and 2 years of follow-up and comparison

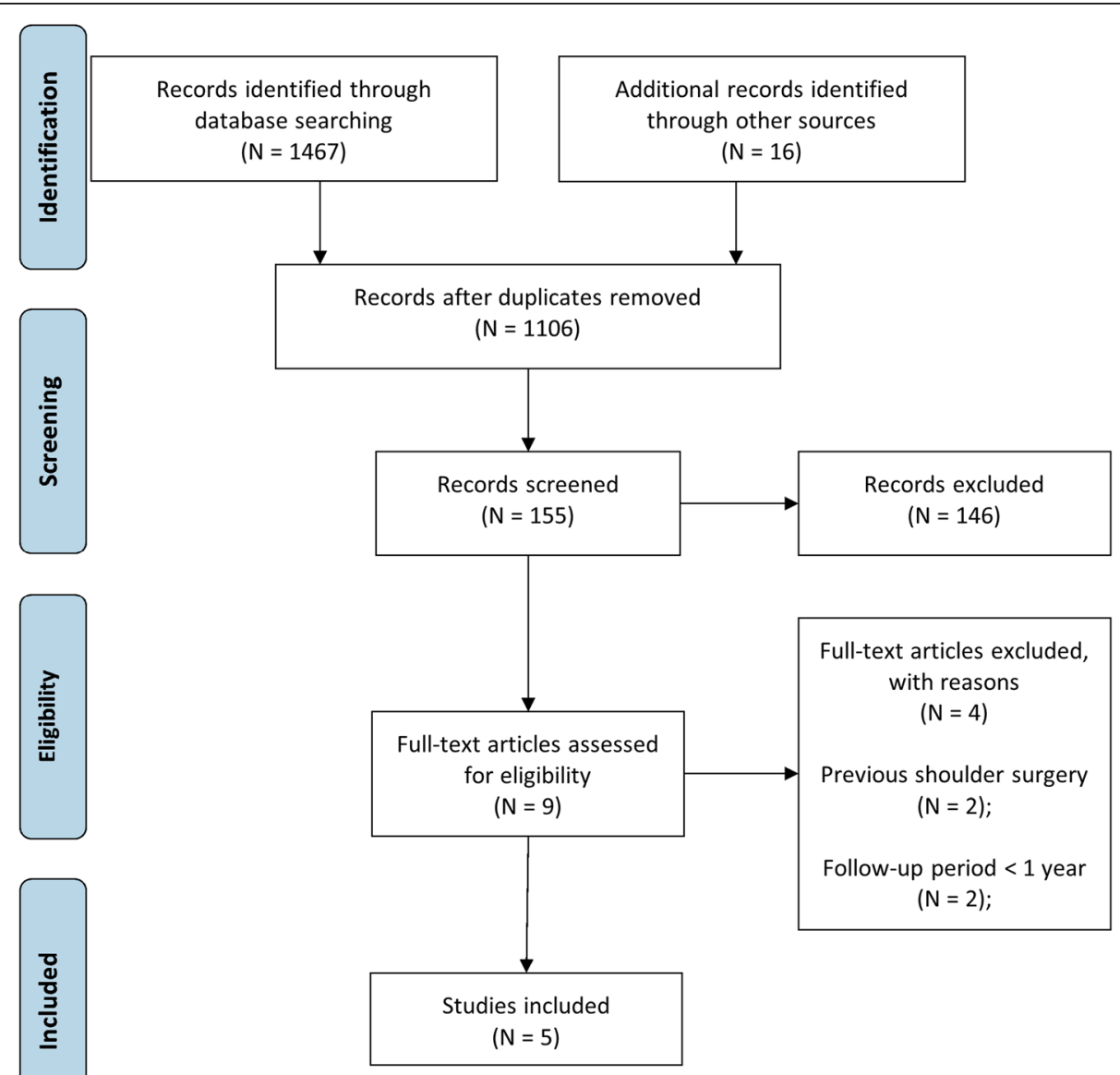

Fig. 1 PRISMA 2009 flow diagram 
Table 1 Demographics

\begin{tabular}{|c|c|c|c|c|c|c|c|c|c|c|}
\hline \multirow[t]{2}{*}{ AUTHORS } & \multirow{2}{*}{$\begin{array}{l}\text { GEOGRAPHIC } \\
\text { AREA }\end{array}$} & \multirow{2}{*}{$\begin{array}{l}\text { No OF } \\
\text { INVOLVED } \\
\text { CENTERS }\end{array}$} & \multicolumn{3}{|c|}{ PARTICIPANTS } & \multirow[t]{2}{*}{ AGE } & \multirow[t]{2}{*}{ SEX } & \multirow{2}{*}{$\begin{array}{l}\text { FOLLOW- } \\
\text { UP }\end{array}$} & \multirow{2}{*}{$\begin{array}{l}\text { CLINICAL } \\
\text { OUTCOMES }\end{array}$} & \multirow[t]{2}{*}{ STRUCTURAL OUTCOMES } \\
\hline & & & $\begin{array}{l}\text { At } \\
\text { baseline }\end{array}$ & $\begin{array}{l}\text { Lost at } \\
\text { follow- } \\
\text { up }\end{array}$ & $\begin{array}{l}\text { At } \\
\text { maximum } \\
\text { follow-up }\end{array}$ & & & & & \\
\hline $\begin{array}{l}\text { Kukkonen } \\
\text { et al, } 2014 \\
\text { [29] }\end{array}$ & Europe & 1 & 180 & 13 & 167 & $\begin{array}{l}S G= \\
65 \\
C G= \\
65\end{array}$ & $\begin{array}{l}\mathrm{SG}= \\
26 \mathrm{M}, \\
29 \mathrm{~F} \\
\mathrm{CG}= \\
24 \mathrm{M} ; \\
31 \mathrm{~F}\end{array}$ & $\begin{array}{l}12 \\
\text { months }\end{array}$ & CMS & - \\
\hline $\begin{array}{l}\text { Kukkonen } \\
\text { et al., } 2015 \\
\text { [14] }\end{array}$ & & & & & & & $\begin{array}{l}\mathrm{SG}= \\
29 \mathrm{M}, \\
25 \mathrm{~F} \\
\mathrm{CG}= \\
22 \mathrm{M} ; \\
33 \mathrm{~F}\end{array}$ & $\begin{array}{l}24 \\
\text { months }\end{array}$ & CMS, VAS & MRl at 24 months \\
\hline $\begin{array}{l}\text { Lambers- } \\
\text { Heerspink } \\
\text { et al., } 2015 \\
\text { [15] }\end{array}$ & Europe & 1 & 56 & 11 & 45 & $\begin{array}{l}S G= \\
61 \\
C G= \\
61\end{array}$ & $\begin{array}{l}\mathrm{SG}= \\
15 \mathrm{M} ; \\
10 \mathrm{~F} \\
\mathrm{CG}= \\
20 \mathrm{M} ; \\
11 \mathrm{~F}\end{array}$ & $\begin{array}{l}12 \\
\text { months }\end{array}$ & CMS, VAS & MRl at 12 months \\
\hline $\begin{array}{l}\text { Moosmayer } \\
\text { et al, } 2010 \\
{[12]}\end{array}$ & Europe & 1 & 103 & 10 & 93 & $\begin{array}{l}\mathrm{SG}= \\
59 \\
\mathrm{CG}=\end{array}$ & $\begin{array}{l}\text { SG: } \\
37 \mathrm{M} ; \\
15 \mathrm{~F}\end{array}$ & $\begin{array}{l}12 \\
\text { months }\end{array}$ & $\begin{array}{l}\text { CMS, ASES, } \\
\text { VAS }\end{array}$ & MRI at 12 months \\
\hline $\begin{array}{l}\text { Moosmayer } \\
\text { et al., } 2014 \\
\text { [30] }\end{array}$ & & & & 10 & 93 & & $\begin{array}{l}\text { CG: } \\
36 \mathrm{M} ; \\
15 \mathrm{~F}\end{array}$ & $\begin{array}{l}24 \text { and } \\
60 \\
\text { months }\end{array}$ & & $\begin{array}{l}\text { MRI at } 12 \text { months and } \\
\text { Ultrasound at } 60 \text { months }\end{array}$ \\
\hline $\begin{array}{l}\text { Moosmayer } \\
\text { et al., } 2019 \\
\text { [13] }\end{array}$ & & & & 12 & 91 & & & $\begin{array}{l}120 \\
\text { months }\end{array}$ & & $\begin{array}{l}\text { MRI at } 12 \text { months and } \\
\text { Ultrasound at } 60 \text { months } \\
\text { and } 120 \text { months }\end{array}$ \\
\hline
\end{tabular}

SG Surgical group, CG Conservative group, M Male, F Female, MRI Magnetic Resonance Imaging, CMS Constant-Murley score, VAS Visual analogue scale, ASES American shoulder and elbow surgery

for structural outcome was possible at one year of follow-up. Further study characteristics are summarised in Table 1.

Study characteristics at different follow-up times are summarised in Table 2.

\section{Meta-analysis results}

Meta-analysis was performed to investigate the potential differences between conservative and surgical management for patients with RC tears in terms of CMS (at 12 months and 24 months of follow-up) and VAS pain score (at 12 months of follow-up). Each study evaluated the shoulder function through several outcomes (e.g., American Society of Shoulder and Elbow Surgeon, Painfree abduction, Dutch Simple Shoulder Test, Range of Motion). However, the comparison between all the included articles was possible only in terms of CMS and the VAS pain score.

\section{CMS score at 12 months of follow-up}

The CMS score at 12 months of follow-up was recorded in 3 studies [12, 15, 30]. Data from 257 patients (126 in the surgical group and 131 in the conservative group) were presented in Table 3 and depicted graphically in

Table 2 Studies characteristics at different follow-up times

\begin{tabular}{|c|c|c|c|c|c|}
\hline & \multirow[t]{2}{*}{$\begin{array}{l}\text { Follow-up, } \\
\text { months }\end{array}$} & \multirow{2}{*}{$\begin{array}{l}\text { Patients at } \\
12 \text { months } \\
\text { of follow-up, } n\end{array}$} & \multirow{2}{*}{$\begin{array}{l}\text { Patients at } \\
24 \text { months } \\
\text { of follow-up, } n\end{array}$} & \multicolumn{2}{|c|}{$\begin{array}{l}\text { Patients included in quantitative analysis } \\
\text { at the maximum follow-up period, } n\end{array}$} \\
\hline & & & & Conservative group & Surgical group \\
\hline Kukkonen et al 2014, [29] & $3,6,12$ & 110 & - & 55 & 55 \\
\hline Kukkonen et al 2015, [14] & $3,6,12,24$ & - & 109 & 55 & 54 \\
\hline Lambers-Heerspink et al 2015, [15] & 12 & 45 & - & 25 & 20 \\
\hline Moosmayer et al 2010, [12] & 6,12 & 102 & - & 51 & 51 \\
\hline Moosmayer et al 2014, [30] & $6,12,24,60$ & - & 101 & 51 & 51 \\
\hline
\end{tabular}


Table 3 Constant and Murley Score (mean \pm SD) at baseline, 12 and 24 months of follow-up

\begin{tabular}{|c|c|c|c|c|c|c|}
\hline \multicolumn{7}{|c|}{ Constant and Murley score at 1 -year follow-up (range 0 to 100) } \\
\hline \multirow[t]{2}{*}{ Authors } & \multicolumn{2}{|c|}{ Moosmayer 2010, [4] } & \multicolumn{2}{|c|}{ Kukkonen 2014, [3] } & \multicolumn{2}{|c|}{ Lambers Heerspink 2015, [5] } \\
\hline & $\begin{array}{l}\text { Surgical group } \\
(n=51)\end{array}$ & $\begin{array}{l}\text { Conservative group } \\
(n=51)\end{array}$ & $\begin{array}{l}\text { Surgical group } \\
(n=55)\end{array}$ & $\begin{array}{l}\text { Conservative group } \\
(n=55)\end{array}$ & $\begin{array}{l}\text { Surgical group } \\
(n=20)\end{array}$ & $\begin{array}{l}\text { Conservative group } \\
(n=25)\end{array}$ \\
\hline Baseline & $35.3 \pm 13.2$ & $38.4 \pm 14.2$ & $58.1 \pm 13.2$ & $57.1 \pm 16.7$ & $55.6 \pm 18.4$ & $56.9 \pm 15.0$ \\
\hline 12 months & $77.7 \pm 13.4$ & $70.3 \pm 19,1$ & $77.9 \pm 12.1$ & $74.1 \pm 14.2$ & $81.9 \pm 15.6$ & $73.7 \pm 18.4$ \\
\hline \multicolumn{7}{|c|}{ Constant and Murley score at 2-year follow-up (range 0 to 100) } \\
\hline \multirow[t]{2}{*}{ Authors } & \multicolumn{2}{|c|}{ Moosmayer 2014, [6] } & \multicolumn{2}{|c|}{ Kukkonen 2015, [2] } & \multirow{2}{*}{\multicolumn{2}{|c|}{-}} \\
\hline & $\begin{array}{l}\text { Surgical group } \\
(n=51)\end{array}$ & $\begin{array}{l}\text { Conservative group } \\
(n=51)\end{array}$ & $\begin{array}{l}\text { Surgical group } \\
(n=54)\end{array}$ & $\begin{array}{l}\text { Conservative group } \\
(n=55)\end{array}$ & & \\
\hline 24 months & $79.3 \pm 13.6$ & $77.7 \pm 14.9$ & $80.6 \pm 15.4$ & $76.2 \pm 15.5$ & & \\
\hline
\end{tabular}

Fig. 2. The average value at 12 months of follow-up was $79.2 \pm 13.7$ in the surgery group and $72.7 \pm 17.2$ in the conservative group. Results showed statistically significant differences between the CMS measured at one year of follow-up in favour of surgical RC repair compared with patients treated conservatively $(5.55,95 \%$ CI 1.91 to 9.19; $P=0.003, \mathrm{I}^{2}=0 \%$ ). Because of the low heterogeneity of the cohort under examination, a fixed effect was used.

\section{CMS score at 24 months of follow-up}

The CMS score at 24 months of follow-up was recorded in 2 studies [14, 31]. 211 patients (105 in the surgical group, and 106 in the conservative group) were included (Table 3). The average value at 24 months follow-up was $80 \pm 15$ in the surgery group and $77 \pm 15$ in the conservative group. Results showed that there are no statistically significant differences between the CMS measured at two years of follow-up between patients undergoing surgical RC repair and patients treated conservatively (2.93, 95\% CI -1.07 to $6.94 ; P=0.15, \mathrm{I}^{2}=0 \%$ ) (Fig. 3). The homogeneity of the sample population allowed a fixed effect to be used.

\section{VAS score at 12 months of follow-up}

The VAS pain score at 12 months of follow-up was recorded in 2 studies [12, 15]. 147 patients (71 in the surgical group, and 76 in the conservative group) were included (Table 4). The mean of VAS pain score was $1.4 \pm 1.6$ in the surgery group and $2.4 \pm 1.9$ in the conservative group. The surgery group provided superior results when compared to the conservative group in terms of VAS pain score at 12 months of follow-up (-1.08, 95\% CI -1.58 to $-0.58 ; P<0.001, \mathrm{I}^{2}=0 \%$ ) (Fig. 4 ). The homogeneity of the sample population allowed a fixed effect to be used.

The VAS pain score at 24 months of follow-up was not performed because the VAS pain score in one article has been reported only graphically, therefore it was not possible to accurately extract numerical data [14].

\section{Structural outcomes at $\mathbf{1 2}$ months of follow-up}

MRI results were reported for the surgical group at 12 months of follow-up in 2 studies [12, 15]. 69 patients (50 and 19 respectively) were included. 24 (35\%) retears were found (10 and 14 respectively) at a 1-year followup.

\section{Quality assessment results}

Please see the risk of bias summary presented in Fig. 5.

All the studies were judged as having a low risk of bias for selection bias because they reported the use of an appropriate method to generate the allocation schedule. Due to the lack of blinding of the patient and personnel, all the studies were judged as high risk for performance bias. Moreover, two out three patient's cohorts were

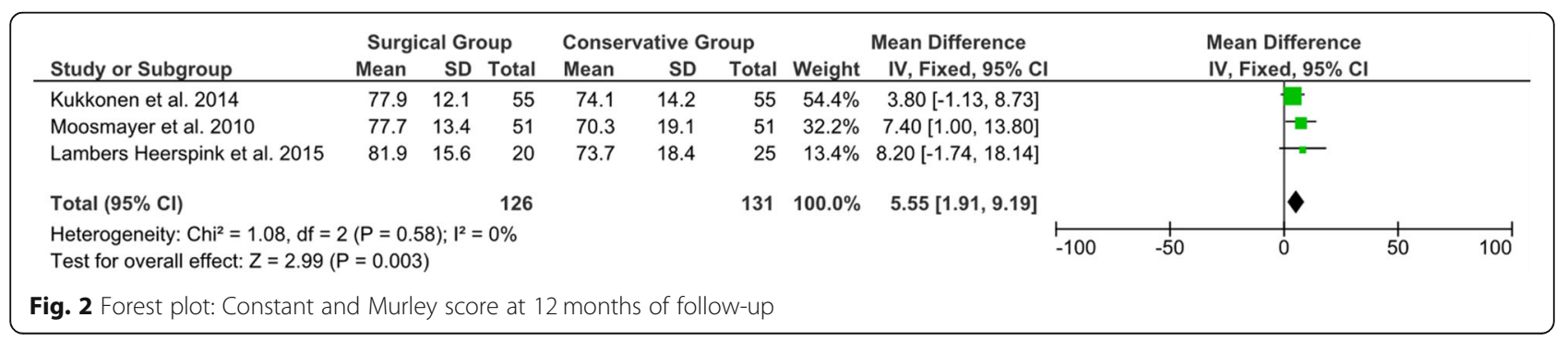




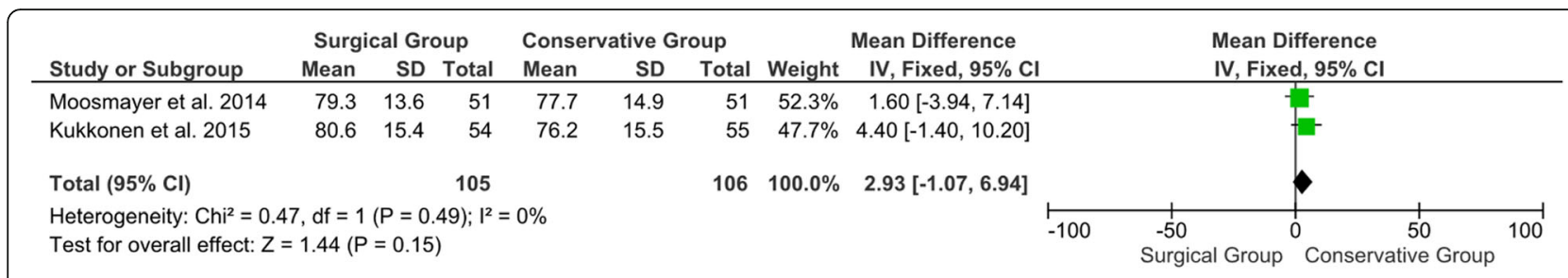

Fig. 3 Forest plot: Constant and Murley score at 24 months of follow-up

judge as having a high risk for the lack of blinding of outcome assessment. In contrast, Kukkonen et al. reported a low risk because the blinding of outcome assessors was ensured. However, we judge all the studies as having a low risk of bias for incomplete outcomes data since they reported less than $20 \%$ loss to follow-up and balanced loss among the groups. Other potential bias was not identified.

We assessed the quality of the results for each analysed variable (CMS at one-year follow-up, CMS at two years follow-up and VAS pain score at one-year followup). The quality of the evidence of the included studies was found to be high both for CMS at one year and two years of follow-up and for VAS pain score at one year of follow-up. We have presented the overall classification of the trials for these three main results in a single summary table of results (Table 5).

\section{Discussions}

$\mathrm{RC}$ tears are one of the most common disabling musculoskeletal disorders with high prevalence rate, and the appropriate treatment is still under debate [38, 39]. According to the American Academy Orthopaedic Surgeons (AAOS) guidelines, surgical RC repair is a valid option for patients with chronic, symptomatic full-thickness RC tears. However, the quality of evidence is unconvincing [40]. On the other hand, there is also a lack of supporting evidence for conservative treatment and, thus, the AAOS recommendations remain inconclusive [40]. Moreover, the

Table 4 VAS pain score (mean \pm SD) at baseline and 12 months of follow-up

\begin{tabular}{|c|c|c|c|c|}
\hline \multicolumn{5}{|c|}{ VAS pain score at 1 -year follow-up (range 0 to 10 ) } \\
\hline \multirow[t]{2}{*}{ Authors } & \multicolumn{2}{|c|}{ Moosmayer 2010, [12] } & \multicolumn{2}{|c|}{$\begin{array}{l}\text { Lambers Heerspink 2015, } \\
\text { [15] }\end{array}$} \\
\hline & $\begin{array}{l}\text { Surgical } \\
\text { group } \\
(n=51)\end{array}$ & $\begin{array}{l}\text { Conservative } \\
\text { group } \\
(n=51)\end{array}$ & $\begin{array}{l}\text { Surgical } \\
\text { group } \\
(n=20)\end{array}$ & $\begin{array}{l}\text { Conservative } \\
\text { group } \\
(n=25)\end{array}$ \\
\hline Baseline & $5.6 \pm 2.0$ & $5.3 \pm 1.9$ & $6.7 \pm 1.7$ & $6.3 \pm 1.3$ \\
\hline $\begin{array}{l}12 \\
\text { months }\end{array}$ & $0.5 \pm 1.2$ & $1.6 \pm 1.6$ & $2.2 \pm 1.9$ & $3.2 \pm 2.1$ \\
\hline
\end{tabular}

superiority of surgical over the conservative treatment is challenging to demonstrate, due to heterogeneity of studies' findings.

In the recent literature, three meta-analyses comparing the surgical and conservative treatment of RC tears are available, in which studies from up to June 2015, October 2016 and March 2018 were included [32-34]. Two of these compared surgical versus conservative management of full-thickness RC tears [32, 33], whereas the third added the evaluation of the subacromial decompression for the management of chronic/degenerative tears of the RC [34]. However, all the previous meta-analyses limited the comparison between surgical and conservative management at the short-term of follow-up ( $\leq 1$ year). Moreover, they did not consider the percentage of retears in the surgical group.

In our meta-analysis, we performed the comparison between conservative and surgical management for patients with RC tears in terms of CMS (at 12 months and 24 months of follow-up) and VAS pain score (at 12 months of follow-up). One of the included randomised clinical trials reported results at $1,2,5$ and 10 years of follow-up. The inclusion of this article allows us to perform the first comparison at two years of follow-up [14, 31]. Our meta-analysis provides the first comparison in the medium-term of follow-up in terms of CMS. These findings are similar to those measured in the short-term follow-up. Notably, significant differences in CMS were found only at 1-year follow-up in favour of the surgical group compared with the conservative group (Fig. 2, Fig. 3). Moreover, a better VAS pain was observed in favour of patients undergoing surgical repair at one year of follow-up (Fig. 4).

In the Norwegian study [31], at two years of followup, clinical outcomes were comparable for both surgical and conservative treatments; at five years of follow-up [31] both groups improved in term of clinical outcomes, but the CMS increased significantly in the surgical group; and at ten years of follow-up [13], clinical outcomes of patients undergoing surgical repair remained stable over time while the clinical outcomes of patients treated conservatively decreased, 


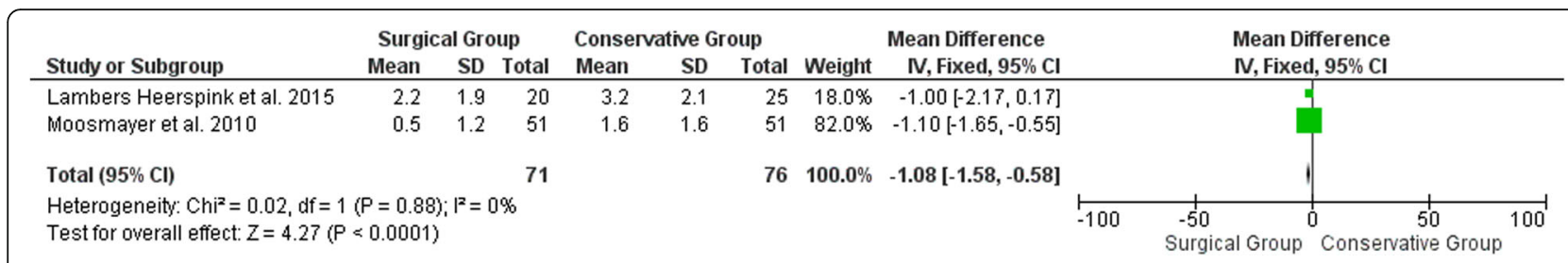

Fig. 4 Forest plot: VAS pain score at 12 months of follow-up

leading to the necessity of surgery in 14 of 51 patients (27\%).

A hypothesis proposed to explain this phenomenon in the long-term is based on the inherent disadvantages of conservative treatment. Indeed, although the potential complications of surgical treatment (e.g., postoperative stiffness, infection) are not negligible, the conservative treatment does not restore the tendon, and this increases the risk of degeneration of shoulder tendons over time [41]. The strengths of this systematic review include the search strategy and the inclusion of only Level-1 studies.

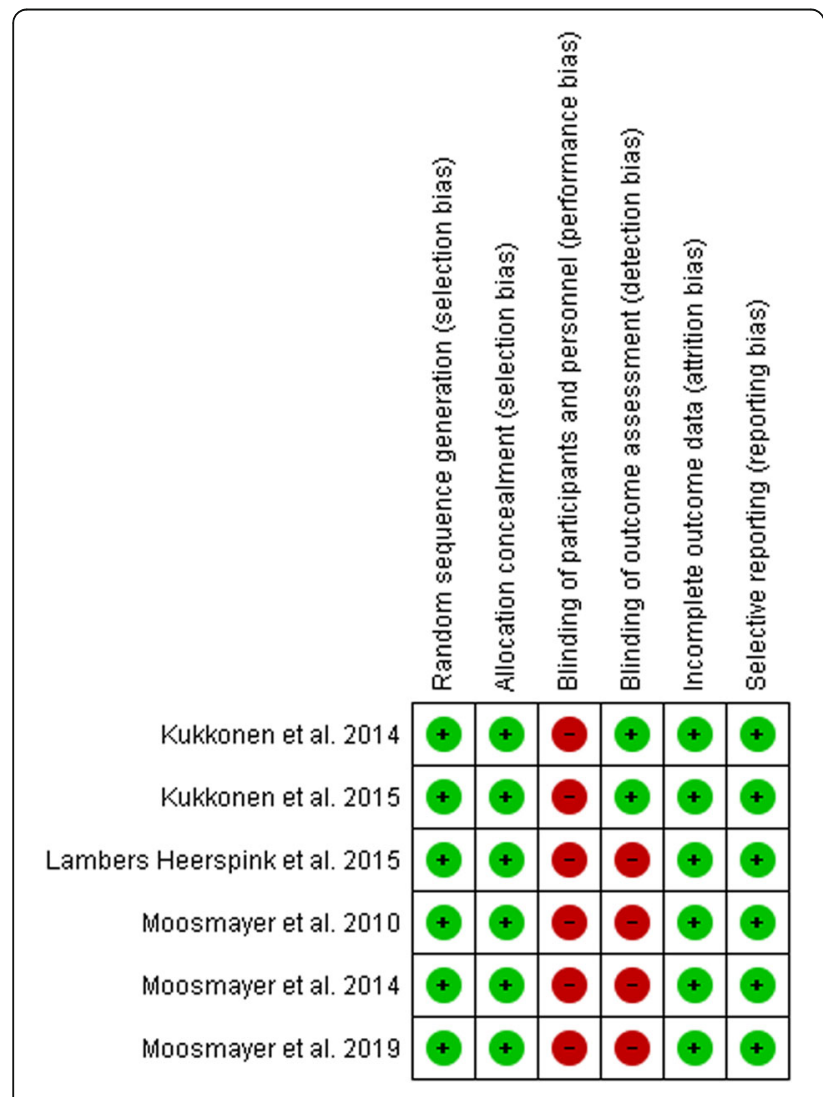

Fig. 5 Risk of bias assessment
Nevertheless, there are several limitations. For instance, an extensive heterogeneity was found in the cohorts of patients analysed. Two studies enrolled patients with isolated supraspinatus tears [14, 30], one study enrolled patients with varying tears of RC (both infraspinatus, subscapularis and supraspinatus tears) [15]. In contrast, two did not specify the type of lesion [12, 31]. Moreover, due to the lack of information on the RC tear characteristics (e.g. tear size) in many studies, we were not able to conduct a subgroup analysis. The comparison of the type of intervention was challenging. One study added three corticosteroid injections to the standardised rehabilitation protocol in the conservative group [15]. Moreover, the number of sessions and the duration of physical therapy were not determined. Different surgical procedures were performed among the included studies: one cohort of patients was treated through arthroscopy [14, 30], whereas the other ones with open and mini-open approach $[12,15,31]$. Even though these techniques result to be equivalent, it is not clear whether the type of intervention may influence the functional outcomes and pain perception. Therefore, these results should be interpreted with caution. Besides, the comparison between muscle atrophy, adipose degeneration, size of the tear, and muscle retraction has not been reported in the included studies. This has prevented us from conducting a more rigorous quantitative analysis adjusted for these contextual factors. The long-term comparison of MRI findings is needed in future studies to investigate the potential impact of treatments on the progression of glenohumeral osteoarthritis, fatty infiltration, narrowing of the acromion-humeral distance and increasing of the size of the lesion.

\section{Conclusions}

This is the first meta-analysis that compared surgical and conservative management for RC tears at two years of follow-up. The data reported in the included studies did not allow to draw a conclusion about muscle atrophy and the integrity of the repaired tendon. Further highquality level-I randomised controlled trials at longer 
Table 5 GRADE: Summary of Findings

\begin{tabular}{lll}
\hline Outcomes & No. of participants (studies) & Certainty of the evidence (GRADE) \\
\hline Constant-Murley score at 1-year of follow-up & 257 & $\oplus \oplus \oplus \oplus$ \\
Constant-Murley score at 2-year of follow-up & $(3 \mathrm{RCTs})$ & $\mathrm{HIGH}$ \\
& 211 & $\oplus \oplus \oplus \oplus$ \\
VAS pain score & $(2 \mathrm{RCTs})$ & $\mathrm{HIGH}$ \\
& 147 & $\oplus \oplus \oplus \oplus$ \\
\hline
\end{tabular}

GRADE Working Group grades of evidence

High certainty: We are very confident that the true effect lies close to that of the estimate of the effect

Moderate certainty: We are moderately confident in the effect estimate: The true effect is likely to be close to the estimate of the effect, but there is a possibility that it is substantially different

Low certainty: Our confidence in the effect estimate is limited: The true effect may be substantially different from the estimate of the effect

Very low certainty: We have very little confidence in the effect estimate: The true effect is likely to be substantially different from the estimate of effect

term follow-up are needed to evaluate whether surgical and conservative treatment provide comparable longterm results.

\section{Abbreviations}

RC: Rotator Cuff; CMS: Constant-Murley score; PRISMA: Preferred Reporting Items for Systematic Reviews and Meta-Analyses; AAOS: American Academy Orthopaedic Surgeons

\section{Acknowledgements}

Not applicable.

\section{Authors' contributions}

UGL and VD conceived and supervised the study. LRA and VC carried out the search process and data collection. AB and ES assessed the quality of the study. LRA and AC drafted the manuscript. All the authors have read and approved the final manuscript.

\section{Authors' information}

Not applicable.

\section{Funding}

This work has been funded by the Italian Ministry of Health in the framework of RICERCA FINALIZZATA 2016 (PE-2016-02364894). The role of the funding body was in the design of the study.

\section{Availability of data and materials}

The datasets used and/or analysed during the current study available from the corresponding author on reasonable request.

\section{Ethics approval and consent to participate}

Not applicable.

\section{Consent for publication}

Not applicable.

\section{Competing interests}

UGL and AB are members of the Editorial Board of BMC Musculoskeletal Disorders. The remaining authors declare that they have no conflict of interest.

\section{Author details}

${ }^{1}$ Department of Orthopaedics and Trauma Surgery, Campus Bio-Medico University of Rome, Via Alvaro del Portillo, 200, 00128 Trigoria, Rome, Italy. ${ }^{2}$ Unit of Measurements and Biomedical Instrumentation, Campus Bio-Medico University of Rome, Via Alvaro del Portillo, 200, 00128 Trigoria, Rome, Italy.
Received: 1 December 2019 Accepted: 14 December 2020

Published online: 08 January 2021

\section{References}

1. Longo UG, Berton A, Papapietro N, Maffulli N, Denaro V. Epidemiology, genetics and biological factors of rotator cuff tears. Med Sport Sci. 2012:57:1-9.

2. Longo UG, Facchinetti G, Marchetti A, Candela V, Risi Ambrogioni L, Faldetta A, De Marinis MG, Denaro V. Sleep disturbance and rotator cuff tears: a systematic review. Medicina (Kaunas) 2019;55(8):453-63.

3. Mitchell C, Adebajo A, Hay E, Carr A. Shoulder pain: diagnosis and management in primary care. BMJ. 2005;331(7525):1124-8.

4. Rees JL. The pathogenesis and surgical treatment of tears of the rotator cuff. J Bone Joint Surg Br. 2008;90(7):827-32.

5. Colvin AC, Egorova N, Harrison AK, Moskowitz A, Flatow EL. National trends in rotator cuff repair. J Bone Joint Surg Am. 2012;94(3):227-33.

6. Longo UG, Salvatore G, Rizzello G, Berton A, Ciuffreda M, Candela V, Denaro $V$. The burden of rotator cuff surgery in Italy: a nationwide registry study. Arch Orthop Trauma Surg. 2017;137(2):217-24.

7. Yamamoto A, Takagishi K, Osawa T, Yanagawa T, Nakajima D, Shitara H, Kobayashi T. Prevalence and risk factors of a rotator cuff tear in the general population. J Shoulder Elb Surg. 2010;19(1):116-20.

8. Paloneva J, Koskela S, Kautiainen H, Vanhala M, Kiviranta I. Consumption of medical resources and outcome of shoulder disorders in primary health care consulters. BMC Musculoskelet Disord. 2013;14:3.

9. Longo UG, Franceschi F, Ruzzini L, Rabitti C, Morini S, Maffulli N, Denaro V. Histopathology of the supraspinatus tendon in rotator cuff tears. Am J Sports Med. 2008;36(3):533-8.

10. Salvatore G, Longo UG, Candela V, Berton A, Migliorini F, Petrillo S, Ambrogioni LR, Denaro V. Epidemiology of rotator cuff surgery in Italy: regional variation in access to health care. Results from a 14-year nationwide registry. Musculoskelet Surg. 2019;104(3):329-35.

11. Franceschi F, Papalia R, Palumbo A, Del Buono A, Maffulli N, Denaro V. Operative management of partial- and full-thickness rotator cuff tears. Med Sport Sci. 2012;57:100-13.

12. Moosmayer S, Lund G, Seljom U, Svege I, Hennig T, Tariq R, Smith HJ. Comparison between surgery and physiotherapy in the treatment of small and medium-sized tears of the rotator cuff: a randomised controlled study of 103 patients with one-year follow-up. J Bone Joint Surg Br. 2010;92(1):83-91.

13. Moosmayer S, Lund G, Seljom US, Haldorsen B, Svege IC, Hennig T, Pripp $\mathrm{AH}$, Smith HJ. At a 10-year follow-up, tendon repair is superior to physiotherapy in the treatment of small and medium-sized rotator cuff tears. J Bone Joint Surg Am. 2019;101(12):1050-60.

14. Kukkonen J, Joukainen A, Lehtinen J, Mattila KT, Tuominen EK, Kauko T, Äärimaa V. Treatment of nontraumatic rotator cuff tears: a randomized controlled trial with two years of clinical and imaging follow-up. J Bone Joint Surg Am. 2015;97(21):1729-37.

15. Lambers Heerspink FO, van Raay JJ, Koorevaar RC, van Eerden PJ, Westerbeek RE, van't Riet E, van den Akker-Scheek I, Diercks RL. Comparing surgical repair with conservative treatment for degenerative rotator cuff tears: a randomized controlled trial. J Shoulder Elb Surg. 2015;24(8):1274-81. 
16. Ackmann T, Schneider KN, Schorn D, Rickert C, Gosheger G, Liem D. Comparison of efficacy of supraspinatus tendon tears diagnostic tests: a prospective study on the "full-can," the "empty-can," and the "Whipple" tests. Musculoskelet Surg. 2019. Epub ahead of print.

17. Walter SG, Stadler T, Thomas TS, Thomas W. Advanced rotator cuff tear score (ARoCuS): a multi-scaled tool for the classification and description of rotator cuff tears. Musculoskelet Surg. 2019;103(1):37-45.

18. Chona DV, Lakomkin N, Lott A, Workman AD, Henry AC, Kuntz AF, Huffman GR, Glaser DL. The timing of retears after arthroscopic rotator cuff repair. J Shoulder Elb Surg. 2017;26(11):2054-9.

19. Chillemi C, Dei Giudici L, Mantovani M, Osimani M, Gumina S. Rotator cuff failure after surgery: an all-arthroscopic transosseous approach. Musculoskelet Surg. 2018;102(Suppl 1):3-12.

20. Franceschi F, Longo UG, Ruzzini L, Rizzello G, Maffulli N, Denaro V. Soft tissue tenodesis of the long head of the biceps tendon associated to the Roman bridge repair. BMC Musculoskelet Disord. 2008;9:78.

21. Longo UG, Franceschi F, Spiezia F, Marinozzi A, Maffulli N, Denaro V. The low-profile Roman bridge technique for knotless double-row repair of the rotator cuff. Arch Orthop Trauma Surg. 2011;131(3):357-61.

22. Franceschi F, Longo UG, Ruzzini L, Rizzello G, Maffulli N, Denaro V. The Roman bridge: a "double pulley - suture bridges" technique for rotator cuff repair. BMC Musculoskelet Disord. 2007;8:123.

23. Dunn WR, Kuhn JE, Sanders R, An Q, Baumgarten KM, Bishop JY, Brophy RH, Carey JL, Harrell F, Holloway BG, et al. 2013 Neer award: predictors of failure of nonoperative treatment of chronic, symptomatic, full-thickness rotator cuff tears. J Shoulder Elb Surg. 2016;25(8):1303-11.

24. Goldberg BA, Nowinski RJ, Matsen FA. Outcome of nonoperative management of full-thickness rotator cuff tears. Clin Orthop Relat Res. 2001; 382:99-107.

25. Zingg PO, Jost B, Sukthankar A, Buhler M, Pfirrmann CW, Gerber C. Clinical and structural outcomes of nonoperative management of massive rotator cuff tears. J Bone Joint Surg Am. 2007;89(9):1928-34.

26. Carnevale A, Longo UG, Schena E, Massaroni C, Lo Presti D, Berton A, Candela V, Denaro V. Wearable systems for shoulder kinematics assessment: a systematic review. BMC Musculoskelet Disord. 2019;20(1):546.

27. Longo UG, Franceschi F, Berton A, Maffulli N, Droena V. Conservative treatment and rotator cuff tear progression. Med Sport Sci. 2012;57:90-9.

28. Fukuda $\mathrm{H}$. The management of partial-thickness tears of the rotator cuff. J Bone Joint Surg Br. 2003;85(1):3-.

29. Burkhart SS. Arthroscopic treatment of massive rotator cuff tears. Clinical results and biomechanical rationale. Clin Orthop Relat Res. 1991;(267):45-56.

30. Kukkonen J, Joukainen A, Lehtinen J, Mattila KT, Tuominen EK, Kauko T, Aärimaa $V$. Treatment of non-traumatic rotator cuff tears: a randomised controlled trial with one-year clinical results. Bone Joint J. 2014;96-B(1): 75-81.

31. Moosmayer S, Lund G, Seljom US, Haldorsen B, Svege IC, Hennig T, Pripp $\mathrm{AH}$, Smith HJ. Tendon repair compared with physiotherapy in the treatment of rotator cuff tears: a randomized controlled study in 103 cases with a fiveyear follow-up. J Bone Joint Surg Am. 2014;96(18):1504-14.

32. Ryösä A, Laimi K, Äärimaa V, Lehtimäki K, Kukkonen J, Saltychev M. Surgery or conservative treatment for rotator cuff tear: a meta-analysis. Disabil Rehabil. 2017;39(14):1357-63.

33. Piper CC, Hughes AJ, Ma Y, Wang H, Neviaser AS. Operative versus nonoperative treatment for the management of full-thickness rotator cuff tears: a systematic review and meta-analysis. J Shoulder Elb Surg. 2018;27(3): 572-6.

34. Schemitsch $C$, Chahal J, Vicente $M$, Nowak $L$, Flurin PH, Lambers Heerspink F, Henry P, Nauth A. Surgical repair. Bone Joint J. 2019;101-B(9):1100-6.

35. Moher D, Liberati A, Tetzlaff J, Altman DG, Group P. Preferred reporting items for systematic reviews and meta-analyses: the PRISMA statement. Int J Surg. 2010;8(5):336-41.

36. Schmidt L, Shokraneh F, Steinhausen K, Adams CE. Introducing RAPTOR: RevMan parsing tool for reviewers. Syst Rev. 2019;8(1):151.

37. Higgins JP, Altman DG, Gøtzsche PC, Jüni $P$, Moher D, Oxman AD, Savovic J, Schulz KF, Weeks L, Sterne JA, et al. The Cochrane Collaboration's tool for assessing risk of bias in randomised trials. BMJ. 2011;343:d5928.

38. Urwin M, Symmons D, Allison T, Brammah T, Busby $H$, Roxby $M$, Simmons A, Williams G. Estimating the burden of musculoskeletal disorders in the community: the comparative prevalence of symptoms at different anatomical sites, and the relation to social deprivation. Ann Rheum Dis. 1998;57(11):649-55.
39. Roquelaure $Y, \mathrm{Ha}$ C, Leclerc A, Touranchet A, Sauteron M, Melchior M, Imbernon E, Goldberg M. Epidemiologic surveillance of upper-extremity musculoskeletal disorders in the working population. Arthritis Rheum. 2006; 55(5):765-78.

40. Tashjian RZ. AAOS clinical practice guideline: optimizing the management of rotator cuff problems. J Am Acad Orthop Surg. 2011;19(6):380-3.

41. Keener JD, Galatz LM, Teefey SA, Middleton WD, Steger-May K, StobbsCucchi G, Patton R, Yamaguchi K. A prospective evaluation of survivorship of asymptomatic degenerative rotator cuff tears. J Bone Joint Surg Am. 2015;97(2):89-98.

\section{Publisher's Note}

Springer Nature remains neutral with regard to jurisdictional claims in published maps and institutional affiliations.
Ready to submit your research? Choose BMC and benefit from:

- fast, convenient online submission

- thorough peer review by experienced researchers in your field

- rapid publication on acceptance

- support for research data, including large and complex data types

- gold Open Access which fosters wider collaboration and increased citations

- maximum visibility for your research: over $100 \mathrm{M}$ website views per year

At BMC, research is always in progress.

Learn more biomedcentral.com/submissions 